\title{
Artigo
}

\section{As emoções do médico e as implicações para a prática clínica}

\author{
Laura Marques Castelhano (i)* \\ Liliana Liviano Wahba $\mathbb{C}$ \\ Pontifícia Universidade Católica de São Paulo. São Paulo, SP, Brasil
}

\begin{abstract}
Resumo: 0 objetivo deste artigo foi investigar as emoções do médico e as implicações para a prática clínica. Utilizou-se o método misto, avaliando, na fase quantitativa, trinta médicos com atuação em consultório. Para a fase qualitativa, foram escolhidos quatro médicos para o estudo de caso. Os resultados mostraram que médicos mais velhos, com mais tempo de formação, que ficam mais tempo em consulta com o paciente sentiram-se mais impactados diante dos estímulos emocionais; e os que trabalham mais horas semanais no consultório perceberam os estímulos de forma menos prazerosa. Esses dados foram confirmados pelos agrupamentos dos quatro clusters. Efetuou-se a análise de caso com um representante de cada cluster. Os resultados revelaram que as emoções podem influenciar atitudes e percepções do médico na relação com o paciente.
\end{abstract}

Palavras-chave: psicologia médica, relação médico-paciente, emoções.

\section{Introdução}

As emoções influenciam as vivências e as formas de ser dos indivíduos. São programas de ação complexos e, em grande medida, automatizados que afetam as percepções (Damásio, 2006; 2011). Desse modo, são de difícil controle (Jung, 1921/2009) e têm papel importante na dinâmica relacional, pois interferem nos mecanismos projetivos e na relação médico-paciente. (Balint, 1988).

O encontro clínico é um momento em que médico e paciente ligam-se e interagem também por meio das emoções numa interação em que as fantasias e as projeções desempenham um papel importante na comunicação, escolha, e adesão a um tratamento.

Historicamente a visão predominante na medicina é a de que decisões clínicas devem ser objetivas e livres de comprometimento emocional. O modelo biomédico ainda separa a compreensão da fisiologia e da patologia do corpo, das vivências e das emoções (De Marco, 2012). No entanto, as teorias sobre as emoções, principalmente com o avanço das neurociências, mostram a prevalência da interdependência entre a emoção e cognição, apesar de haver divergências no entendimento de como esses dois fenômenos interagem (Damásio, 2006; Ekman, 2001; Frijda, 1994; Lazarus, 1991; LeDoux, 2001; Zajonc, 1984).

De acordo com Damásio (2011) e LeDoux (2001), emoção e cognição são funções que fazem parte de um mesmo sistema. Segundo Damásio (2006; 2011), apesar de as emoções não serem atos racionais, elas, por meio dos sentimentos, desencadeiam o processo cognitivo. As emoções, muitas vezes, são deflagradas sem uma participação intencional (LeDoux, 2001), por outro lado

\footnotetext{
* Endereço para correspondência: lmcastelhano@pucsp.br
}

os sentimentos são "as percepções compostas daquilo que ocorre em nosso corpo e na nossa mente quando uma emoção está em curso" (Damásio, 2011, p. 142).

De acordo com Damásio (2006) a ideia de uma "razão pura", em que as emoções são vistas como "intrusas" nos processos analíticos, é um mito. Para o autor, a emoção participa dos processos de escolha e tomada de decisão, e está presente tanto no momento em que se armazena uma informação quanto na hora de selecionar as possíveis respostas.

Damásio (2011) estuda as emoções como programas de ação complexos e, em grande medida, automatizados, que têm efeito sobre o nosso corpo, e sobre a nossa mente. Equipara-se a Jung (1921/2009), que considera a emoção/ afeto um estado caracterizado por inervações perceptíveis do corpo e uma perturbação peculiar do curso das ideias. Os dois autores consideram que os sentimento é uma função valorativa da emoção.

A teoria junguiana destaca a influência dos aspectos emocionais na vida dos sujeitos. A importância dos afetos/ emoções para a vida psíquica deve-se principalmente ao fato de que uma de suas funções é conectar os componentes da psique - sensações, ideias, memórias e julgamentos -, concedendo a cada um uma "tonalidade afetiva" comum (Jung, 1904/1994).

Uma atitude, segundo Jung (1921/2009), é uma predisposição que tem presente uma constelação subjetiva do complexo e uma combinação de fatores ou conteúdos psíquicos que determinam a ação; sempre apresenta um ponto direcional que pode ser consciente ou inconsciente. De acordo com Stein (2006, p. 52), "quanto mais tempo uma atitude persiste, e quanto mais frequentemente ela for chamada a satisfazer as exigências do meio, mais habitual ela se torna". 
Atitudes habituais, e exigências do meio, direcionam a construção da persona do indivíduo, a qual tem uma função adaptativa e é, em grande parte, a necessidade de "parecer ser" para "pertencer". Em grande parte, ela é social, pois são os outros, mais do que a própria pessoa, os responsáveis por sua formação (Jung, 1916/1991).

A projeção está ligada à própria dinâmica da psique, conectando o mundo interior ao mundo exterior. É um processo inconsciente automático, por meio do qual um conteúdo inconsciente é transferido, de modo que pareça pertencer ao objeto (Jung, 1933/2012). Pertencente à esfera das relações, a projeção está presente em todos os relacionamentos humanos, seu conteúdo geralmente é carregado de emoção e, por ser um processo automático e inconsciente, dificilmente é submetido ao controle da consciência.

Esta pesquisa centra-se no estudo de emoções de processos cognitivos e afetivos (Ekman, 2001; Damásio, 2006) e na dinâmica de vinculações interpessoais inconscientes (Jung, 1946/2011), aplicando-se à relação médico-paciente (Balint, 1988; De Marco, 2012).

Tal relação apresenta características projetivas peculiares que recebem o nome, na literatura, de transferência e contratransferência. Freud (1912/1996c), o primeiro a esquematizar o conceito de transferência, desde seus primeiros estudos já pressentia que existia algo importante para o processo terapêutico na relação médico-paciente. Ponto crucial do trabalho analítico, a transferência era, para Freud (1905/1996a), uma exigência indispensável para o tratamento e impossível de evitar. "O tratamento psicanalítico não cria a transferência, mas simplesmente a revela, como a tantas outras coisas ocultas na vida anímica" (Freud, 1905/1996a, p. 73).

A análise do fenômeno da transferência em Freud (1905/1996a, 1912/1996c, 1920/1980) trazia dois pontos importantes. Primeiro: a constatação de que as experiências psíquicas de seus pacientes eram revividas no vínculo atual, no presente, com o médico (Freud, 1912/1996d). Segundo: a observação de que os pacientes que não pudessem recordar a totalidade do que neles se achava reprimido, repetiam emoções e situações indesejadas, revivendo-as sob a pressão de uma compulsão, como se fosse uma experiência nova atuada na esfera da transferência na relação do paciente com o médico (Freud, 1920/1980).

O termo "contratransferência" foi utilizado pela primeira vez por Freud (1910/1996b) para referir-se às reações do médico diante da transferência do paciente. Considerado um fenômeno da interação e, portanto, difícil de ser evitado, o médico, segundo Freud (1912/1996d, 1915/1996e), para uma boa prática, deveria estar ciente dos complexos, pois estes poderiam interferir na compreensão do que o paciente lhe dizia e na sua percepção analítica.

Ao analisarmos a contratransferência em Jung (1929/1985, 1946/2011), dois aspectos são importantes: o processo dialético e a transformação mútua, e como isso está relacionado com a interação médico-paciente.

A dialética na relação médico-paciente é ressaltada por Jung (1929/1985) porque, para ele, no encontro, dois sistemas psíquicos se inter-relacionam e por meio desse contato produzem-se novas sínteses. Não é somente a personalidade do paciente que ganha destaque no tratamento psíquico, mas também a do médico - o que vai além do que este diz ou pensa, ainda que isso não possa ser menosprezado.

Sob a luz das recentes evidências nos campos da pesquisa cérebro-mente, Wiener (2009) observa que os comentários de Jung parecem bastante modernos, uma vez que ele intuiu que médicos e analistas provavelmente são afetados por seus pacientes.

Balint (1988) foi um dos grandes responsáveis por reaproximar alguns dos fenômenos existentes na análise e na clínica psicanalítica à medicina e fazer dessa aplicação um instrumento possível para qualquer médico. Sua preocupação (Balint, 1988) era discutir e propor uma solução para a problemática relação médico-paciente e, para isso, estendeu os conceitos utilizados por Freud, Ferenczi e Jung sobre transferência e contratransferência ao processo para qualquer relacionamento entre médico e paciente.

Transferência e contratransferência, segundo Balint (1988), estão em constante influência; por isso, o médico deve ser capacitado para reconhecer suas reações e seu modo de lidar com o paciente para compreender seu sentido dinâmico.

Segundo Balint (1988), o médico cria, consciente ou inconscientemente, uma atitude particular em relação a seus pacientes. $\mathrm{O}$ autor chamou esse fenômeno de função apostólica. "A personalidade do médico e os interesses subjetivos podem exercer uma influência decisiva naquilo que ele nota e registra a respeito de seus pacientes" (Balint, 1988, p. 47).

Os médicos, impulsionados pela função apostólica, necessitam fazer todo o possível para criar em seus pacientes, e em si mesmos, a impressão de que são bons e úteis em sua profissão. Essa é uma imagem idealizada, pois todo médico tem seus temperamentos e idiossincrasias (Balint, 1988).

De acordo com Hughes (2000), a pedra angular do tratamento na medicina é a aliança terapêutica, mas esta pode ser distorcida pelos desejos e expectativas do paciente e do médico. Portanto, a boa prática inclui uma atitude questionadora e um entendimento de que médicos e pacientes são afetados na relação, que se desenvolve de forma mais efetiva, segundo Balint (1988), quando os envolvidos possuem um conhecimento do outro e de suas influências.

Segundo Serour, Al Othman e Al Khalifah (2009), o médico deve compreender que, na relação com o paciente, os "problemas" não cabem exclusivamente aos pacientes. Assim, ele deve analisar o encontro para 
identificar suas causas. De acordo com Lorenzetti, Jacques, Donovan, Cottrell e Buck (2013), encontros difíceis podem estar associados ao médico, ao paciente ou a ambos.

As primeiras reações dos médicos em relação aos seus pacientes, segundo Croskerry, Abbass e Wu (2010) são, muitas vezes, emocionais e ocorrem de forma automática, influenciando, posteriormente, o processamento de informações, o julgamento e a tomada de decisão.

Roter, Frankel, Hall e Sluyter (2006), ao analisarem consultas gravadas, observaram que a maioria dos pacientes captou a emotividade do médico e teve suas respostas determinadas pelo modo como ele fazia uma pergunta e reagia às suas emoções. Street e Haidet (2011), ao compararem as percepções dos médicos sobre o estado de saúde de seus pacientes e a avaliação do próprio paciente, identificaram uma diferença significativa entre as percepções de ambos. Os autores ressaltam que os médicos muitas vezes têm uma má compreensão de seus pacientes, o que pode influenciar a sua comunicação e a tomada de decisão.

Ser médico é lidar constantemente com o fato de estar inserido em uma relação e "qualquer que seja a atitude adotada pelo médico, ela influirá permanentemente em sua relação com o paciente em questão . . . esse tipo de desenvolvimento reveste-se de grande importância emocional para o médico" (Balint, 1988, p. 189).

O objetivo geral deste estudo é explorar as emoções dos médicos e compreender as implicações para a prática clínica. Os objetivos específicos são: analisar as respostas emocionais dos médicos, investigar a percepção dos médicos sobre as emoções na prática clínica, identificar as emoções despertadas pelos pacientes e compreender as estratégias para lidar com elas.

\section{Método}

Nesta pesquisa, utilizou-se o método misto sequencial explanatório, identificado por Creswell e Clark (2013), em que a análise de dados quantitativos orientaram a análise de dados qualitativos.

\section{Participantes}

Participaram da primeira fase do estudo trinta médicos, homens e mulheres, de diversas especialidades. Foram utilizados como critérios de inclusão: dedicar parte (ou a totalidade) de seu tempo ao atendimento no consultório; ter, no mínimo, dois anos de experiência após a conclusão da residência médica; atuar em medicina convencional. Na segunda fase, foram escolhidos quatro médicos para realização de entrevista.

\section{Procedimento de coleta}

Antes de iniciar a pesquisa, que foi realizada no local de trabalho do médico (consultório) e dividida em duas fases de coleta - quantitativa e qualitativa -, foram realizados dois pré-testes para verificação dos instrumentos.

Para avaliação quantitativa, foram utilizados os seguintes instrumentos:

- Questionário sociodemográfico - composto pelas questões: sexo, idade, tempo de formado, tempo total de horas semanais dedicadas ao trabalho, horas semanais dedicadas ao trabalho no consultório, número de pacientes/ dia e tempo médio de atendimento/ consulta.

- International Affective Picture System (IAPS) - instrumento composto por imagens divididas em três categorias (agradáveis, desagradáveis e neutras) para avaliar a resposta emocional do médico. Para este estudo, foram selecionadas 36 imagens, que possuíam como tema o relacionamento interpessoal, divididas em: 12 desagradáveis; 12 agradáveis e 12 neutras. As respostas emocionais aos estímulos são classificadas através do Self-Assessment Manikin (SAM), composto por três escalas: prazer, alerta e dominância; apenas as duas primeiras foram utilizadas neste estudo. Cada escala possui gradações emocionais, que variam de 1 a 9. Os participantes marcam um " $\times$ " sobre o item que mais se aproxima da avaliação emocional induzida pela imagem do IAPS. A escala Alerta mede a intensidade emocional, que pode ir de "tenso e impactado" a "calmo e relaxado". A escala Prazer mede a valência emocional, que pode ir de "prazer e satisfação" (agradável/ positiva) a "desprazer e insatisfação" (desagradável/ negativa).

A validação e normatização para população brasileira do IAPS foi realizado por Ribeiro, Pompéia e Bueno (2004) e é utilizada em diversos estudos sobre as emoções. A utilização foi autorizada pelos autores.

Para avaliação qualitativa, foi realizada a entrevista semiestruturada com questões para investigar: a percepção dos médicos sobre as emoções na prática clínica, as emoções despertadas pelos pacientes e as estratégias para lidar com as emoções.

A coleta de dados quantitativos realizada com trinta médicos seguiu o seguinte procedimento: informações sobre a pesquisa, objetivos e sequência da aplicação; informação sobre a confidencialidade e a possibilidade de se retirar da pesquisa a qualquer momento; assinatura do termo de consentimento; aplicação dos instrumentos. Essa aplicação durou em média vinte minutos e os dados qualitativos foram coletados após a análise estatística e escolha de quatro médicos para análise aprofundada mediante entrevista. As respostas dadas foram gravadas e transcritas e cada entrevista teve uma média de duração de trinta minutos. 


\section{Procedimento de análise}

Para a análise quantitativa, foram utilizados testes estatísticos e os programas SPSS.17 (Statistical Package for the Social Science) e SPAD (Systeme Portable pour l'Analyse des Données) para tratamento dos dados. O SPSS.17 foi utilizado para a realização dos seguintes testes: teste de uma média; teste de duas médias para amostras independentes; análise de variância; e correlação de Pearson. Foram aplicados testes estatísticos para um nível de significância de 0,05 . O SPAD foi utilizado para a comparação de médias para amostras independentes, análise de variância e classificação hierárquica para construção de cluster.

Foram criados quatro clusters que agruparam indivíduos por similaridades em relação à pontuação no IAPS, sendo escolhido um participante por cluster para a análise de estudos de caso, o que somou quatro médicos, identificados por nomes fictícios.

A análise dos casos foi realizada por meio de categorias temáticas, relacionadas com os objetivos da pesquisa: a percepção dos médicos sobre as emoções na prática clínica, as emoções despertadas pelos pacientes, as estratégias para lidar com as emoções.

A pesquisa foi realizada de acordo com os requerimentos éticos em pesquisa envolvendo seres humanos preconizados pela Resolução 196/1996 do Conselho Nacional de Saúde e pelo Regimento dos Comitês de Ética em Pesquisa.

\section{Resultados quantitativos}

Analisaram-se as relações entre a respostas emocionais dos médicos, uma vez obtidas pelo IAPS as variáveis sociodemográficas deste estudo. A comparação da média da amostra das duas escalas do IAPS, Alerta e Prazer, e a variável "sexo" foi realizada por meio do teste de duas médias, demonstrando que não há diferença significativa entre homens e mulheres na relação com as escalas.

A verificação da correlação entre as escalas Alerta e Prazer, do IAPS, e as variáveis "idade", "tempo de formado", "tempo total de horas semanais dedicadas ao trabalho", "horas semanais dedicadas ao trabalho no consultório", "número de pacientes/ dia" e "tempo médio de atendimento/ consulta" foi realizada por meio do coeficiente de Pearson, estatística descritiva que mede o grau da correlação entre duas variáveis.

Observou-se que o coeficiente de Pearson entre idade e a escala Alerta foi igual a $+0,35$, o que indica uma relação positiva e moderada. Isso significa que quanto maior a idade, maior a sua pontuação. $\mathrm{O}$ mesmo ocorreu entre tempo de formado e Alerta, em que o coeficiente de Pearson foi igual a $+0,32$, indicando também uma relação positiva e moderada, que significa que quanto maior o tempo de formado, maior a pontuação nessa escala. Da mesma forma, houve correlação positiva e moderada $(+0,36)$ entre o tempo médio de atendimento e Alerta, mostrando que, quanto maior o tempo de consulta, maior a pontuação em Alerta.

Houve correlação negativa e moderada $(-0,40)$ entre tempo de trabalho (horas semanais trabalhadas) no consultório e a escala Prazer, o que significa que quanto mais horas semanais dedicadas ao trabalho no consultório, menor a pontuação em Prazer. Não houve correlação entre o total de horas semanais de trabalho e o número de pacientes atendidos por dia e as escalas Alerta e Prazer.

Os resultados mostaram que algumas tendências nas respostas emocionais dos participantes. Médicos mais velhos, com mais tempo de formados e que ficam mais tempo com o paciente em consulta, sentiram-se mais impactados diante dos estímulos emocionais do que os médicos mais jovens, com menos tempo de formados e que ficam menos tempo em consulta. Médicos que dedicam mais horas semanais ao trabalho no consultório perceberam os estímulos de forma mais negativa e desagradável do que os que dividem seu tempo com atividades no hospital.

Para ampliar a análise dos resultados, foi utilizado o tratamento estatístico para agrupamento de clusters, o quais reuniram participantes por proximidade ou afastamento da média em relação às duas escalas, Alerta e Prazer, do IAPS. Utilizou-se instrumento estatístico para comprovar que o agrupamento entre os clusters foi considerado fidedigno estatisticamente, garantindo que existe homogeneidade interna (entre si) e heterogeneidade externa (entre eles). Optou-se por agrupar os participantes em quatro clusters distintos. Essa separação forneceu um embasamento para selecionar os participantes que fizeram parte da análise qualitativa (Figura 1).

Seguiu-se a análise, comparando as respostas dos médicos por cluster com o parâmetro populacional. (Tabela 1)

O cluster 1 não apresentou diferença significativa em relação aos parâmetros populacionais nas duas escalas. Já os clusters 2, 3 e 4 apresentaram diferença significativa. O cluster 2 possui a pontuação mais alta na escala Alerta e a menor pontuação/ média na escala Prazer; o cluster 3 possui a média mais baixa na escala Alerta; o cluster 4 é agrupamento mais distante da média da população na escala Prazer e o com maior pontuação entre os clusters. 


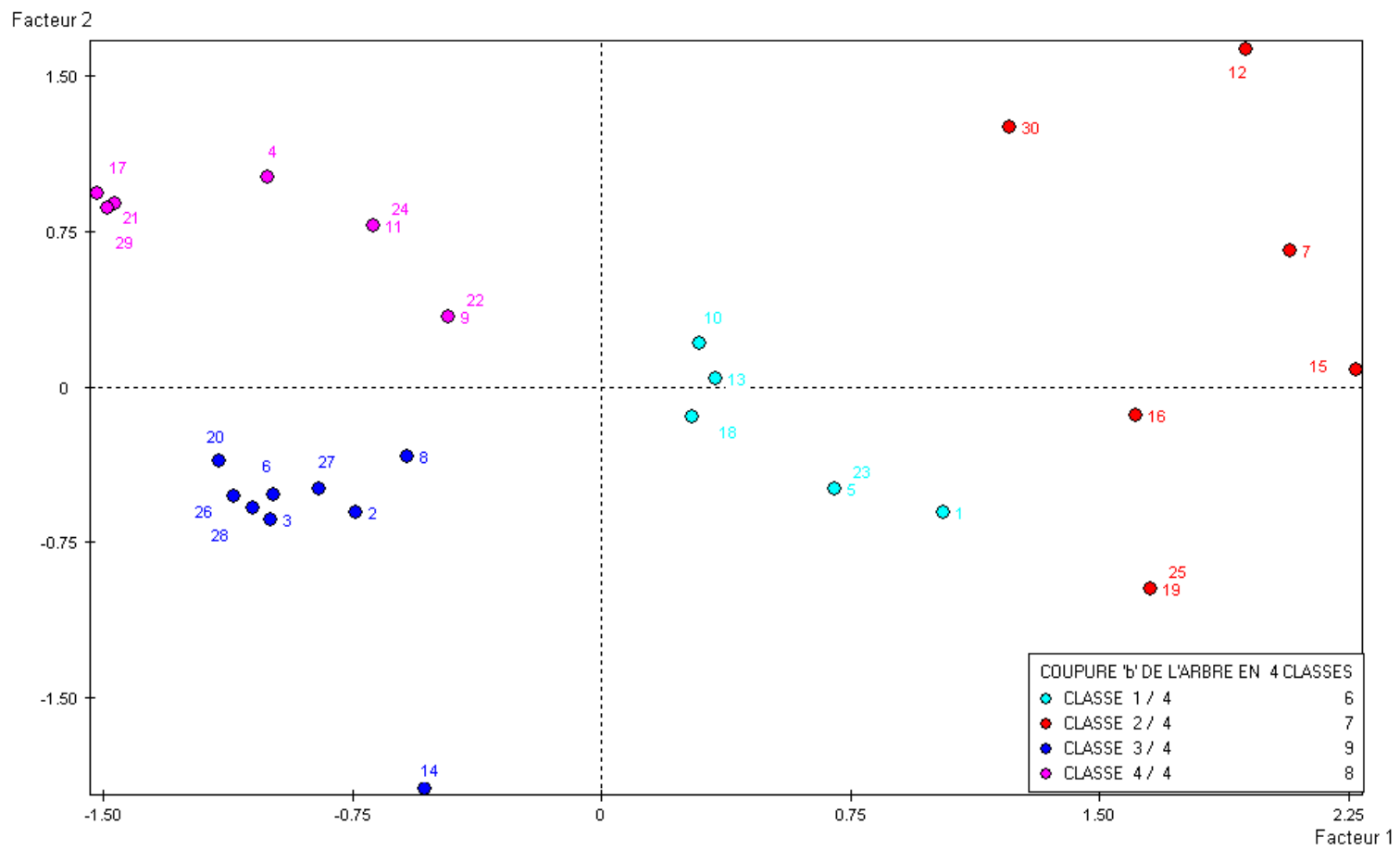

Figura 1. Agrupamento de cluster das respostas emocionais dos médicos, segundo International Affective Picture System (IAPS).

Fonte: Elaborada pelas autoras.

Tabela 1. Comparação dos clusters com os parâmetros populacionais nas escalas Prazer e Alerta do International Affective Picture System (IAPS)

\begin{tabular}{ccccccccc}
\hline Alerta & $N$ & Média & Desvio Padrão & Erro padrão & $\mu$ & Diferença & $t$ & $p$ \\
\hline Cluster 1 & 6 & 5,01 & 0,097 & 0,040 & 4,91 & 0,099 & 2,499 & 0,055 \\
Cluster 2 & 7 & 6,12 & 0,722 & 0,273 & 4,91 & 1,213 & 4,443 & 0,004 \\
Cluster 3 & 9 & 3,77 & 0,273 & 0,091 & 4,91 & $-1,135$ & $-12,475$ & 0,000 \\
Cluster 4 & 8 & 4,65 & 0,207 & 0,073 & 4,91 & $-0,261$ & $-3,557$ & 0,009 \\
\hline Prazer & $N$ & Média & Desvio Padrão & Erro padrão & $\mu$ & Diferença & $t$ & $p$ \\
\hline Cluster 1 & 6 & 4,93 & 0,155 & 0,063 & 5,01 & $-0,079$ & $-1,256$ & 0,265 \\
Cluster 2 & 7 & 4,74 & 0,268 & 0,101 & 5,01 & $-0,268$ & $-2,648$ & 0,038 \\
Cluster 3 & 9 & 5,19 & 0,161 & 0,054 & 5,01 & 0,178 & 3,317 & 0,011 \\
Cluster 4 & 8 & 5,56 & 0,171 & 0,060 & 5,01 & 0,553 & 9,135 & 0,000 \\
\hline
\end{tabular}

Fonte: Elaborada pelas autoras.

\section{Resultados qualitativos}

Foram escolhidos quatro médicos, um representante de cada cluster, para análise em profundidade. Analisou-se mediante entrevistas a percepção das emoções na prática clínica, as emoções despertadas na relação com os pacientes e estratégias para lidar com as emoções. Na sequência, a análise resumida dos casos típicos de cada cluster.

\section{Marcos}

Marcos, representante do cluster 1, que agrupou médicos com pontuação na média em relação ao índice Alerta e Prazer, demonstrou interesse e abertura para falar de suas emoções, mesmo que em alguns momentos tenha encontrado dificuldade para expressá-las. Ele relatou que faz terapia, disse que foi buscar este apoio por conta das demandas emocionais de seu trabalho.

- Percepção das emoções na prática clínica: as emoções parecem ter um lugar importante na prática de Marcos, que se esforça para percebê-las. Para ele, as emoções auxiliam em seu trabalho como médico e devem ser sempre utilizadas de forma a beneficiar o paciente. Observa que o médico precisa ficar muito atento às características do vínculo, pois isso interfere na relação com o paciente.

- Emoções despertadas na relação com os pacientes: Marcos relata sentir-se constantemente cobrado e sempre querer resolver tudo, fator que precisa constantemente trabalhar e sobre o qual 
necessita refletir. Relata o medo de errar quando está diante dos pacientes. Para ele, paciente que nega a doença não é aderente às orientações e não compreende a necessidade de sua participação no tratamento, o que resulta em uma sensação de impotência e insegurança: “. . . é como se eu fosse impotente, na verdade". Este tipo de paciente mobiliza emoções como raiva, mas também pena, dependendo da evolução do caso e do vínculo que se mantenha com ele. Pode chegar a gerar uma sensação de afastamento: "são pacientes que impossibilitam o vínculo". O paciente que busca apoio e se preocupa com a saúde gera em Marcos um sentimento de prazer e realização.

- Estratégias para lidar com as emoções: Marcos tende a responsabilizar-se; sente-se impotente, o que gera ansiedade; mas depois há uma tentativa de compreensão por meio da reflexão e da racionalização. Utiliza-se de recursos de autoconhecimento sobre os seus processos emocionais, auxiliados pelo trabalho que vem desenvolvendo na terapia.

\section{Daniel}

Daniel é representante do cluster 2, que agrupou médicos com maior impacto aos estímulos emocionais (alto alerta) e baixo Prazer. Trata-se dos mais velhos, que dedicam mais tempo ao trabalho no consultório e ficam mais tempo com o paciente nas consultas. Durante a entrevista ficou desconfortável com as questões referentes às emoções, e isso repercutiu em suas respostas, já que as perguntas precisaram ser repetidas algumas vezes.

- Percepção das emoções na prática clínica: Daniel acredita que as emoções podem influenciar a sua prática, mas que não deve permitir que isso aconteça. A sua percepção é de que a emoção influencia o tratamento de modo negativo. Por isso, sua atitude é de controle. "Não deixo que afete [emoção] o meu trabalho, hoje já sei bem discernir e controlar". Refere que poucas coisas o afetam verdadeiramente em sua prática médica. - Emoções despertadas na relação com os pacientes: Daniel precisou ser indagado mais de uma vez para conseguir falar sobre suas emoções. Relata que a sensação mais presente em sua prática é a insegurança. Segundo ele, pacientes o afetam de modo negativo quando têm uma postura arrogante, reclamam ou já trazem informações e só esperam dele uma validação do diagnóstico de outro médico; é aquele que questiona a sua autoridade e o seu saber: "Percebe-se uma arrogância na postura quando eles entram no consultório". Por outro lado, o paciente que o afeta de maneira positiva é aquele que, de alguma maneira, ele consegue conduzir, que se deixa controlar e parece respeitá-lo:
"Quando gosto, gosto. Vejo de longe, já na sala de espera". Apesar de Daniel considerar que certos pacientes geram mais sensações positivas do que outros, ressalta que não existem pacientes que não despertem dificuldades.

- Estratégias para lidar com as emoções: para Daniel, a sobrevivência como médico exigiu dele uma postura de controle diante de suas emoções; segundo ele, um aprendizado que os anos de clínica lhe trouxeram: "Quando eu era mais moço, eu tinha taquicardia e emoções importantes". O tempo de clínica e as horas de trabalho fizeram Daniel adaptar-se: "Hoje, não sofro mais". Ao mesmo tempo que diz agir com naturalidade, utiliza estratégias para obter o controle e parece usar da ironia e do cinismo para lidar com algumas situações com os seus pacientes, pois em vários momentos relata estratégias e brincadeiras para lidar com os pacientes que o incomodam. Outro aspecto importante observado em sua atitude diante das situações que geram desconforto é a tentativa de minimizar o seu sofrimento.

\section{Alice}

Alice, representante do cluster 3, que agrupou médicos com menos reatividade emocional (baixo Alerta), foi cordata e mostrou-se muito solícita, mas transmitia uma sensação de abatimento. Em vários momentos, ela teve dificuldade de responder as perguntas e demonstrar o que estava sentindo. Mesmo assim, parecia preocupada em refletir e ser o mais fiel possível às respostas.

- Percepção das emoções na prática clínica: para Alice, perceber as emoções em sua rotina de trabalho é muito importante, pois afeta não só a sua forma de comunicar-se com o paciente, mas também como vai analisar as suas decisões: "[a emoção] influi em tudo". Acredita que os médicos precisam estar preparados para os encontros emocionais intensos em sua atividade.

- Emoções despertadas na relação com os pacientes: Alice relatou situações difíceis com as quais teve que lidar, envolvendo agressões físicas e verbais. Apesar de, num primeiro momento, tentar compreender o paciente e sua situação, conclui que muito difícil. "Não é fácil, mas é uma agressão, um ato de violência .... A gente é muito mal tratado; . . . já apanhei de paciente". Pacientes que duvidam e desconfiam de seu trabalho, questionam e são agressivos despertam mágoa, ressentimento e raiva. Os pacientes que dialogam, trocam e têm uma comunicação fácil e fluída despertam sensações positivas, reforçando sua identidade como médica, pois propiciam a sensação de reconhecimento e utilidade. 
- Estratégias para lidar com as emoções: Alice diz evitar os pacientes que podem lhe causar problemas, repassando ou saindo do caso. Utiliza-se de estratégias de evitação. Conta que em alguns momentos, quando está diante do paciente, tem alguma intuição sobre quem pode lhe causar problemas. Diante da sensação de vulnerabilidade e para suportar as situações difíceis, aparenta utilizar o recurso da racionalização, com ideias e regras de como deve ser a sua conduta como médica: "Lá dentro eu sou uma profissional então, você tem que engolir". Apesar de reconhecer e perceber algumas emoções, demonstra ter pouca compreensão de como utilizar tal reconhecimento. Parece desmotivada e frustrada diante de algumas situações e com baixa energia para alterar aquilo que acredita não poder ser alterado. Talvez pela idade, Alice esteja vivenciando uma fase de questionamento sobre a profissão e a vida de médico.

\section{Miguel}

Miguel é representante do cluster 4, que agrupou médicos com maior índice de Prazer, que atendem mais pacientes e ficam menos tempo com eles. $\mathrm{O}$ encontro com Miguel foi bastante conturbado. Falou muito pouco e às vezes foi monossilábico em suas respostas. Sua sala de espera estava muito cheia, ele corria de um lado para o outro. Houve pouca interação e pouco contato visual.

- Percepção das emoções na prática clínica: Miguel diz que não percebe suficientemente as emoções, pois não pensa muito sobre elas; acredita que isso demandaria tempo e a rotina do trabalho não permite isso: "A gente acaba tocando sem pensar muito nas emoções". As emoções, para Miguel, são tidas como negativas para a interação com o paciente e prejudiciais ao atendimento, sendo percebidas como barreiras que precisam ser "colocadas de lado". Possui um entendimento de que o diagnóstico será mais eficaz se conseguir transpor as emoções, pois tem que ser neutro.

- Emoções despertadas na relação com os pacientes: Miguel teve dificuldade de expressar os conteúdos emocionais despertados no encontro com seus pacientes. Para ele, o paciente que causa sensações negativas, sendo mais difícil de atender, é o que leva para a consulta informações colhidas na internet ou com outros médicos. Miguel entende que o fato de o paciente possuir informações, tornando-se mais questionador, desvaloriza o seu trabalho: "O tipo da pessoa que acha que tem razão". O paciente informado, segundo Miguel, quer confrontar o médico e validar as informações que já possui: "Uma pessoa como essa não dá vontade de atender". Esse tipo de paciente acaba demandando mais atenção e mais esforço de Miguel, já que precisa defender uma ideia ou fazer-se entender. O paciente que desperta seu interesse é aquele que busca o seu apoio, aceita o diagnóstico, reconhece e respeita a sua opinião. - Estratégias para lidar com as emoções: Miguel fala que as emoções precisam ser "cercadas". Ele busca neutralidade na interação: "Você tem que ser neutro". Acredita que a maturidade e os anos de clínica tornaram-no menos influenciado pelas emoções. Diz que esse tipo de situação é muito comum no início de carreira, mas o tempo o ajudou. Reforça a ideia de que não é papel do médico preocupar-se com os aspectos emocionais, psicológicos ou subjetivos da doença de um paciente. Miguel parece ter criado defesas no decorrer de seu processo de aprendizado como médico. A concepção de que a emoção afeta o seu julgamento e tratamento coloca-o em uma situação de defesa, em vez de compreensão e entendimento.

\section{Discussão}

O objetivo deste estudo foi explorar as emoções dos médicos e compreender os processos emocionais e implicações para a prática clínica. Nota-se que existe uma distância entre o que se revela no discurso e a forma como o médico reage diante dos impactos emocionais decorrentes da interação com o paciente. Confirmando o trabalho de outros pesquisadores (De Marco, 2012; Kovács, 2003; Roter et al., 2006; Stolper et al., 2010), verificou-se que os médicos, apesar de estarem pouco atentos às suas emoções, são influenciados por elas.

Em relação à dinâmica emocional, os médicos reconhecem que as emoções estão presentes no encontro com o paciente, mas encontram dificuldade para falar sobre elas e refletir sobre "como" e "o que" os afeta. Segundo Ofri (2014), mesmo um médico mais experiente reconhece que as emoções estão presentes no encontro, mas o modo como os médicos processam essas emoções varia.

Duas tendências foram observadas em relação à percepção dos médicos sobre as emoções em sua prática clínica: os que percebem as emoções como um auxiliar no atendimento, utilizando-as como um instrumento; e os que percebem as emoções como negativas e acreditam que elas devam ser negadas.

Os médicos que percebem as emoções como um auxiliar e acreditam que a emoção interfira no diagnóstico e/ou tratamento, demonstram maior preocupação em percebê-las e ficam mais atentos a elas durante o atendimento. Tendem a ser mais reflexivos e interessados em falar sobre suas emoções, mesmo que encontrem dificuldades. Em relação ao paciente, parecem ter mais clareza do que os incomoda, das dificuldades da relação e de sua responsabilidade na interação. 
Na perspectiva junguiana, discute-se o papel de responsabilidade do médico, pois mesmo que este esteja desvinculado dos conteúdos emocionais do paciente, o simples fato de o paciente possuir emoções terá efeitos sobre ele (Jung, 1917/1987).

Porém, reconhecer a emoção como um auxiliar exige do médico uma atenção especial e instrumentos para lidar com o impacto dessas interações, o que nem sempre ele possui. A mobilização afetiva acompanhada da falta de recursos para lidar com as demandas emocionais pode desencadear maior desgaste e desconfiança diante dos vínculos, desencadeando atitudes de distanciamento e estratégias como a evitação e a racionalização. Sentir e perceber as emoções, sem a compreensão de como utilizá-las, pode desencadear momentos de sofrimento. O médico que demonstrou ter mais recursos para lidar com confrontos afetivos pareceu ser mais consciente de suas ações e fragilidades e, dentre as estratégias utilizadas para lidar com as emoções, oscilou entre a reflexão e a racionalização. Atitudes reflexivas ou racionalizadas expressam-se em tentativas de superar dificuldades para ficar atento às suas emoções, mesmo que se reconheça que não é possível fazer isso sempre.

Uma dinâmica diferente foi percebida nos profissionais que perceberam a influência das emoções de modo negativo no encontro com o paciente. Médicos que não acreditam que as emoções interfiram no diagnóstico e/ou tratamento buscam a neutralidade e creem evitar tal influência por meio do autocontrole. Também reconhecem que não ficam atentos a esses aspectos. Demonstraram dificuldade de reconhecer as emoções relacionadas ao paciente, às vezes sem muita diferenciação entre o que os afetava negativamente ou positivamente.

Eles utilizaram como estratégia para lidar com as emoções o controle e a busca pela neutralidade, dizendo que não prestam atenção em suas emoções e agem com naturalidade mesmo nos momentos difíceis. Observou-se que alguns mecanismos de defesa utilizados foram a negação e a ironia. As suas atitudes eram mais racionais e distantes. Eles pareciam incomodar-se mais com as situações em que eram questionados e com a demanda de trabalho excedente que um paciente poderia lhes trazer se lhe fosse dado espaço para falar mais sobre si. $\mathrm{O}$ médico que se mostrou mais fechado emocionalmente na entrevista foi também o que disse ficar menos tempo com o paciente.

Entendendo que as exigências do trabalho do médico são muito altas, as defesas são, até certo ponto, necessárias para lidar com a carga decorrente da profissão (Wahba, 2001). O risco se encontraria no emprego excessivo dessas defesas quando uma persona rígida ao extremo é inconscientemente acompanhada de insegurança e vulnerabilidade sombria. Hopcke (1985) assinala que a persona do médico, "persona medici", composta por autoridade infalível, sabedoria e poderes mágicos, esconde suas imperfeições humanas.
Quando se avalia que os médicos que permanecem mais horas semanais no consultório perceberam os estímulos de forma mais desagradável, percebe-se a intensidade e as exigências do vínculo, e o quanto isso interfere na relação e na motivação dos médicos. A valência, conforme Lang (1995), refere-se a uma escala que varia do agradável/ positivo ao desagradável/ negativo, indicadores processadas de formas diferentes. A valência negativa ativa o sistema aversivo, que de acordo com Watson e Clark (1994), está relacionado com o desprazer, a raiva, a culpa, o medo e o nervosismo.

A relação médico-paciente é, sempre e invariavelmente, resultado de um compromisso entre as "ofertas" e exigências dos pacientes e as respostas do médico (Balint, 1988). Notou-se nas respostas que os médicos responderam com certa frequência a essas exigências, revelando sentimentos como frustração e impotência perante a perda de valorização e a falta do reconhecimento. Os médicos se ressentem da falta de confiança e valorização de alguns pacientes que deixam transparecer insatisfação. Sentimento semelhante também foi observado por Greenfield et al. (2012), que relataram que os médicos sentem-se vulneráveis quando são contestados ou confrontados com outras opiniões.

Observou-se, no relato dos quatro médicos, que os pacientes podem despertar emoções como raiva, decepção e ressentimento, quando questionam, são exigentes e os fazem sentir-se impotentes e inseguros. Em contrapartida, aqueles que os reconhecem como bons profissionais e têm sentimentos de gratidão reforçam o papel como o "salvador" e desencadeiam sentimentos de valia e prazer.

A função apostólica (Balint, 1988), que representa uma atitude comum aos médicos diante de seus pacientes, pode ser usada de maneira defensiva. Quando são impactados por emoções/ afetos, por meio de um processo de racionalização, revalidam a função apostólica e a crença do que o médico precisa "ser"; é comum nos relatos médicos frases como "mas eu sou médico, não tenho afeto nenhum" ou "preciso suportar porque sou médico".

Ao revalidar tal postura, eles se identificam com outros médicos e reconhecem-se como iguais. Em uma rede de identificação, o médico assimila aspectos daquilo que ele aprendeu sobre o que é "ser médico" e assume tais características, geralmente representadas por uma figura distante e sem afetos.

O tempo de prática e a idade do médico, como observado nos resultados, reforçam tais atitudes, que se evidenciam em comportamentos coletivos. Diante dessa situação, os médicos parecem agir de forma mais automática, e com isso podem não perceber uma forte emoção em relação a um paciente. Em decorrência de tais atitudes, que interferem nas relações e no trabalho, diminui-se o prazer e o grau de satisfação.

Há evidências de que a idade altera a resposta emocional diante de estímulos. Grühn e Scheibe (2008) concluíram que os adultos mais velhos percebem as 
figuras como mais negativas e excitantes que os jovens. Pôrto, Bertolucci, Ribeiro e Bueno (2008) observaram que há diferença nos níveis de alerta e valência afetiva entre idosos e jovens e que há uma forte e negativa correlação entre valência afetiva e nível de alerta.

A contratransferência tem um papel importante na dinâmica relacional em profissões que dependem de vínculos, ocasionando respostas emocionais mais ou menos percebidas. Jung (1929/1985, 1946/2011) já havia concluído que não é somente a personalidade do paciente que ganha destaque no tratamento psíquico, mas também a do médico. No entanto, reconhecer a contratransferência não é tarefa fácil. Ainda existe na medicina o modelo em que há uma cisão entre o pensamento racional e a expressão emocional. Essa dificuldade, também observada nas pesquisas de De Marco (2012), constata que apesar dos avanços nas neurociências, a medicina ainda separa o pensamento do corpo, das vivências e das emoções.

A análise mostrou que as emoções podem influenciar atitudes e percepções e interferir na atividade do médico, corroborando pesquisas e estudos atuais sobre as emoções (Damásio, 2006; Ekman, 2001; LeDoux, 2001).

Dirigir o olhar do médico para a compreensão do processo emocional traria ganhos não só para a relação médico-paciente, mas para a própria atividade. A importância de compreender as projeções e a contratransferência no encontro clínico, além de desempenhar um papel importante na compreensão do outro e de si mesmo, também pode interferir nos processos decisórios e impactar no atendimento do paciente.

\section{Considerações finais}

As emoções estão presentes nas interações com o paciente, mas o médico ainda dedica pouco o seu olhar para elas. O modo como médicos percebem as emoções no atendimento interfere em suas atitudes e nos mecanismos de defesa utilizados, porém ainda parece tabu falar sobre o que sente, o que o emociona e o que o afeta.
Mesmo que não percebam, os esses profissionais têm respostas emocionais em relação a seus pacientes, pois seu trabalho envolve desafios relacionais. Refletir sobre as emoções pode propiciar um ganho individual, mas principalmente auxiliar na leitura do "outro" e no modo de julgar e pensar a própria prática.

Persiste na classe médica a valorização de um papel de poder, que submete o paciente a um controle. O médico, para "ser médico", assume esses valores, que o prendem a uma imagem que enfatiza exageradamente a neutralidade e influencia atitudes que podem produzir uma falta de compreensão dos pacientes e suas necessidades como pessoas.

O distanciamento afetivo, que não pode deixar de correr em paralelo ao distanciamento compreensivo, é mais intensamente perceptível em alguns médicos e reforça a persona "sem afetos". Nos médicos em que se percebe uma aproximação maior com o paciente, nota-se uma abertura maior para a reflexão e para um olhar para si.

Em relação à profissão do médico, percebe-se que novas exigências vêm sendo colocadas, inclusive no relacionamento com os pacientes, que também adquiriram outro tipo de perfil. A postura e as atitudes dos médicos estão sendo questionadas, e parece ser urgente repensar um novo papel. As transformações devem ser discutidas do ponto de vista institucional, mas também individual. É necessário que, individualmente, os médicos reavaliem e recuperem a reflexão sobre o sentido do trabalho.

Quando se entende que as defesas são em parte necessárias ao exercício de uma função que tanto sobrecarrega, estratégias de aproximação da psicologia no campo da medicina se fazem necessárias.

Esta pesquisa abre o caminho para que novos estudos sejam aprofundados no tema das emoções e de sua influência na prática médica. Sugere-se que a saúde do médico seja investigada sob o ponto de vista emocional e que se ampliem as discussões sobre a percepção do médico e o impacto nos processos de decisão.

\title{
Doctors' emotions and their implications for clinical practice
}

\begin{abstract}
This article investigated doctors' emotions and the implications for clinical practice. The mixed method was used to quantitatively evaluate thirty doctors with practice in the office. For qualitative analysis, we chose four doctors for the Case Study. The results showed that older doctors with more time after graduation and more time in consultation with the patient felt more impacted by emotional stimuli than other doctors; and that doctors who work more hours per week in the office perceived the stimuli in a more negatively than other doctors. These data were confirmed by groups of four clusters. It was conducted by a case study with a representative of each cluster. The results revealed that emotions could influence doctors' attitudes and perceptions regarding the patient.
\end{abstract}

Keywords: medical psychology, doctor-patient relationship, emotions. 


\section{Las emociones del médico y las implicaciones en la práctica clínica}

Resumen: El objetivo de este artículo fue investigar las emociones del médico y las implicaciones en la práctica clínica. Este estudio utilizó el método mixto y evaluó, en la fase cuantitativa, treinta médicos con actuación en consultorio. Para la fase cualitativa, se eligieron cuatro médicos para el estudio de caso. Los resultados mostraron que los médicos más viejos, con más tiempo de formación y que se quedan más tiempo en consulta con el paciente se sintieron más impactados ante los estímulos emocionales que los otros médicos; y los médicos que trabajan más horas semanales en el consultorio percibieron los estímulos de forma menos agradable. Estos datos fueron confirmados por las agrupaciones de los cuatro clusters. Se realizó el análisis de caso con un representante de cada cluster. Los resultados revelaron que las emociones pueden influir en las actitudes y percepciones del médico en la relación con el paciente.

Palabras clave: psicología médica, relación médico-paciente, emociones.

\section{Les émotions du médecin et les implications pour la pratique clinique}

Résumé : Le but de cet article était d'étudier les émotions du médecin et les implications pour la pratique clinique. Cette étude a utilisé la méthode mixte et a évalué, dans la phase quantitative, trente médecins avec la pratique au bureau. Pour la phase qualitative, quatre médecins ont été choisis pour l'étude de cas. Les résultats ont montré que les médecins plus âgés, avec plusieurs années de formation et qui passent plus de temps en consultation avec le patient, se sentaient plus touchés par les stimuli émotionnels que les autres ; les médecins qui travaillent de longues heures au bureau ont remarqué les stimuli moins agréablement que les autres. Ces données ont été confirmées par les groupements des quatre grappes. L'analyse de cas a pris un représentant de chaque grappe. Les résultats ont montré que les émotions peuvent influencer les attitudes et les perceptions du médecin par rapport au patient.

Mots-clés: psychologie médicale, relation médecin-patient, émotions.

\section{Referências}

Balint, M. (1988). O médico, seu paciente e a doença. Rio de Janeiro, RJ: Atheneu.

Creswell, J. W., \& Clark, V. L. P. (2013). Pesquisa de métodos mistos. Porto Alegre, RS: Penso.

Croskerry, P., Abbass, A., \& Wu, A. (2010). Emotional influences in patient safety. Journal of Patient Safety, 6(4), 199-205. doi: 10.1097/pts.0b013e3181f6c01a

Damásio, A. (2006). O erro de Descartes: emoção, razão e o cérebro humano. São Paulo, SP: Companhia da Letras.

Damásio, A. (2011). E o cérebro criou o homem. São Paulo, SP: Companhia da Letras.

De Marco, M. A. (2012). Comunicação e relação. In M. A. De Marco, C. C Abud, A. C Lucchese, \& V. B Zimmermann, Psicologia médica: abordagem integral do processo saúde-doença (pp. 63-104). Porto Alegre, RS: Artmed.

Ekman, P. (2001). A linguagem das emoções. São Paulo, SP: Lua de Papel.

Freud, S. (1980). Além do princípio de prazer. In Edição standard brasileira das obras psicológicas completas de Sigmund Freud (Vol. 18, pp. 17-85). Rio de Janeiro, RJ: Imago. (Trabalho original publicado em 1920)

Freud, S. (1996a). Fragmentos da análise de um caso sobre a histeria. In Edição standard brasileira das obras psicológicas completas de Sigmund Freud (Vol. 7, pp. 5-76). Rio de Janeiro, RJ: Imago. (Trabalho original publicado em 1905)

Freud, S. (1996b). As perspectivas futuras da terapêutica psicanalítica. In Edição standard brasileira das obras psicológicas completas de Sigmund Freud (Vol. 11, pp. 84-92). Rio de Janeiro, RJ: Imago. (Trabalho original publicado em 1910)

Freud, S. (1996c). Dinâmica da Transferência. In Edição standard brasileira das obras psicológicas completas de Sigmund Freud (Vol. 12, pp. 59-65). Rio de Janeiro, RJ: Imago. (Trabalho original publicado em 1912)

Freud, S. (1996d). Recomendações aos médicos que exercem a psicanálise. In Edição standard brasileira das obras psicológicas completas de Sigmund Freud (Vol. 12, pp. 66-78). Rio de Janeiro, RJ: Imago. (Trabalho original publicado em 1912)

Freud, S. (1996e). Observações sobre o amor transferencial. In Edição standard brasileira das obras psicológicas completas de Sigmund Freud (Vol. 12, pp. 98-109). Rio de Janeiro, RJ: Imago. (Trabalho original publicado em 1915)

Frijda, N. (1994). The Emotions: studies in emotion and social interaction. Paris: Maison de Sciences de l'Homme.

Greenfield, G., Pliskin, J. S., Feder-Bubis, P., Wientroub, S., \& Davidovitch, N. (2012). Patient-physician relationships in second opinion encounters: the 
physicians' perspective. Social Science \& Medicine, 75(7), 1202-1212. doi: 10.1016/j.socscimed.2012.05.026

Grühn, D., \& Scheibe, S. (2008). Age-related differences in valence and arousal ratings of pictures from the International Affective Picture System (IAPS): do ratings become more extreme with age? Behavior Research Methods, 40(2), 512-521. doi: 10.3758/BRM.40.2.512

Hopcke, R. H. (1985). Persona: where sacred meets profane. Boston: Shambhala.

Hughes, P. (2000). Transference and countertransference in communication between doctor and patient. Advances In Psychiatric Treatment, 6(1), 57-64. doi: 10.1192/apt.6.1.57

Jung, C. G. (1985). Os problemas da psicoterapia moderna. In C. G. Jung, A prática da psicoterapia (Obras completas, Vol. 16/1, pp. 66-89). Petrópolis, RJ: Vozes. (Trabalho original publicado em 1929)

Jung, C. G. (1987). Psicologia do inconsciente (Obras completas, Vol. 7/1). Petrópolis, RJ: Vozes. (Trabalho original publicado em 1917)

Jung, C. G. (1991). O eu e o inconsciente (Obras completas, Vol. 7/2). Petrópolis, RJ: Vozes. (Trabalho original publicado em 1916)

Jung, C. G. (1994). Parecer médico sobre um caso de simulação de insanidade mental. In C. G. Jung, Estudos psiquiátricos (Obras completas, Vol. 1, pp. 197-214). Petrópolis, RJ: Vozes. (Trabalho original publicado em 1904)

Jung, C. G. (2009). Tipos psicológicos (Obras completas, Vol. 6). Petrópolis, RJ: Vozes. (Trabalho original publicado em 1921)

Jung, C. G. (2011). A psicologia da transferência. In C. G. Jung, Ab-reação, análise dos sonhos e transferência (Obras completas, Vol. 16/2, pp. 46-215). Petrópolis, RJ: Vozes, 2011. (Trabalho original publicado em 1946)

Jung, C. G. (2012). Sobre os arquétipos do inconsciente coletivo. In C. G. Jung, Os arquétipos e o inconsciente coletivo (Obras completas, Vol. 9/1, pp. 11-50). Petrópolis, RJ: Vozes. (Trabalho original publicado em 1933)

Kovács, M. J. (2003). Educação para morte: temas $e$ reflexões. São Paulo, SP: Casa do Psicólogo.

Lang, P. J. (1995). The emotion probe: studies of motivation end attention. American Psychologist, 50(5), 372-385.

Lazarus, R. S. (1991). Emotion and Adaptation. New York: Guilford.

LeDoux, J. (2001). Cérebro emocional: os misteriosos alicerces da vida emocional. Rio de Janeiro, RJ: Objetiva.

Lorenzetti, R. C., Jacques, M., Donovan, C., Cottrell, O., \& Buck, J. (2013). Managing difficult encounters: understanding physician, patient, and situational factors. American Family Physician, 87(6), 419-425.
Ofri, D. (2014). What doctors feel: how emotions affect the practice of medicine. Boston: Beacon Press.

Pôrto, W. G., Bertolucci, P. H. F., Ribeiro, R. L., \& Bueno, O. F. A. (2008). Um estudo dos relatos afetivos subjetivos a estímulos do International Affective Picture System em uma amostra geriátrica brasileira. Revista de Psiquiatria do Rio Grande do Sul, 30(2), 131-138. doi: 10.1590/ S0101-81082008000300009

Ribeiro, R. L., Pompéia, S., \& Bueno, O. F. A. (2004). Normas brasileiras para o Internacional Affective Picture System (IAPS): comunicação breve. Revista de Psiquiatria do Rio Grande do Sul, 26(2), 190-194. doi: 10.1590/S0101-81082004000200008

Roter, D., Frankel, R., Hall, J., \& Sluyter, D. (2006). The expression of emotion through nonverbal behavior in medical visits: mechanisms and outcomes. Journal of General Internal Medicine, 21(S1), S28-S34. doi: 10.1111/j.1525-1497.2006.00306.x

Serour, M., Al Othman, H. A., \& Al Khalifah, G. (2009). Difficult Patients or difficult doctors: an analysis of problematic consultations. Journal of General Internal Medicine, 6(2), 87-93.

Stein, M. (2006). Jung: o mapa da alma. São Paulo, SP: Cultrix.

Stolper, E., van Leeuwen, Y., van Royen, P., van de Wiel, M., van Bokhoven, M., Houben, P., . . . Dinant, G. (2010). Establishing a European research agenda on 'gut feelings' in general practice. A qualitative study using the nominal group technique. European Journal of General Practice, 16(2), 75-79. doi: 10.3109/13814781003653416

Street, R. L., Jr., \& Haidet P. (2011). How well do doctors know their patients? Factors affecting physician understanding of patients' health beliefs. Journal of General Internal Medicine, 26(1), 21-27.

Wahba, L. L. (2001). Relação médico-paciente: subsídios da psicologia para a educação médica (Tese de Doutorado). Pontifícia Universidade Católica de São Paulo, São Paulo.

Watson, D., \& Clark, L. A. (1994). The Panas-X: manual for the positive and negative affect schedule-expanded form. Iowa: University of Iowa.

Wiener, J. (2009). The Therapeutic Relationship: transference, countertransference, and the making of meaning. College Station: Texas A\&M University Press.

Zajonc, R. (1984). On the primacy of affect. American Psychologist, 39(2), 117-123.

Recebido: $14 / 02 / 2018$

Revisado: 23/02/2019

Aprovado: 23/05/2020 